\title{
Influence of bulky substituents on the regioselective group-transfer reactions of diorganozinc compounds with $N, N^{\prime}$-bis(2,6-di-isopropylphenyl)-1,4-diaza-1,3-butadiene
}

\author{
Elmo Wissing, Klaas van Gorp, Jaap Boersma and Gerard van Koten* \\ Debye Institute, Department of Metal-Mediated Synthesis, Utrecht University, Padualaan 8, 3584 CH Utrecht (Netherlands)
}

(Received November 12, 1993)

\begin{abstract}
Diorganozinc compounds $\mathrm{R}_{2} \mathrm{Zn}\left(\mathrm{R}=\right.$ alkyl or aryl) react with $N, N^{\prime}$-bis(2,6-di-isopropylphenyl)-1,4-diaza-1,3-butadiene, $\left(\mathrm{i}-\mathrm{Pr}_{2} \mathrm{Ph}\right) \mathrm{N}=\mathrm{CHCH}=\mathrm{N}\left(\mathrm{i}-\mathrm{Pr}_{2} \mathrm{Ph}\right)\left(\mathrm{i}-\mathrm{Pr}_{2} \mathrm{Ph}-\mathrm{DAB}\right)$ to give thermally unstable 1:1 condination complexes $\mathrm{R}_{2} \mathrm{Zn}\left(\mathrm{i}-\mathrm{Pr}_{2} \mathrm{Ph}-\mathrm{DAB}\right)$, which subsequently undergo a slow regioselective alkyl or aryl group-transfer reaction from the zinc atom to an imine-nitrogen or a carbon atom of the NCCN system of the $\mathrm{i}-\mathrm{Pr}_{2} \mathrm{Ph}-\mathrm{DAB}$ ligand. In the case of $\mathrm{R}=$ methyl, n-propyl, $\mathrm{n}$-butyl, s-butyl, neopentyl and benzyl, C-alkylation occurs with a subsequent 1,2 hydrogen shift in the amino-imino skeleton affording $\mathrm{RZn}\left[\left(\mathrm{i}-\mathrm{Pr}_{2} \mathrm{Ph}\right) \mathrm{N}-\mathrm{CH}_{2}-\mathrm{CR}=\mathrm{N}\left(\mathrm{i}-\mathrm{Pr}_{2} \mathrm{Ph}\right)\right]$, whereas for $\mathrm{R}=\mathrm{t}$ butyl the C-alkylated product $\mathrm{t}-\mathrm{BuZn}\left[\left(\mathrm{i}-\mathrm{Pr}_{2} \mathrm{Ph}\right) \mathrm{N}-\mathrm{CH}(\mathrm{t}-\mathrm{Bu})-\mathrm{CH}=\mathrm{N}\left(\mathrm{i}-\mathrm{Pr}_{2} \mathrm{Ph}\right)\right]$ is stable. Surprisingly, diphenylzinc reacts with $\mathrm{i}-\mathrm{Pr}_{2} \mathrm{Ph}-\mathrm{DAB}$ exclusively to give the $\mathrm{N}$-arylated product $\mathrm{PhZn}\left[\left(\mathrm{i}-\mathrm{Pr}_{2} \mathrm{Ph}\right) \mathrm{N}=\mathrm{CHCH}=\mathrm{N}(\mathrm{Ph})\left(\mathrm{i}-\mathrm{Pr}_{2} \mathrm{Ph}\right)\right]$.
\end{abstract}

Key words: Organozinc reagents; Regioselective group transfer; Steric effects

\section{Introduction}

1,4-Disubstituted 1,4-diaza-1,3-butadienes $\left(\mathrm{R}^{\prime} \mathrm{N}=\right.$ $\mathrm{CH}-\mathrm{CH}=\mathrm{NR}^{\prime}$ ) have been extensively studied as ligands for transition and main-group metals $[1,2]$. However, recent studies revealed that these heterodienes are versatile synthons in metal-mediated organic synthesis [3-7]. In these applications, reactions of diorganozinc compounds with $\mathrm{R}^{\prime} \mathrm{DAB}\left(\mathrm{R}^{\prime}=\right.$ alkyl) $[8,9]$, which proceed with high regioselectivity, play an essential role. Some examples of such reactions are given in Scheme 1 .

So far, our studies have been restricted to alkyl substituted 1,4-diaza-1,3-butadienes. Mechanistic studies showed that organozinc- $R^{\prime} D A B$ radical intermediates, $\left[R Z n R^{\prime} \mathrm{DAB}\right]^{\prime}$, are likely key intermediates in the reactions shown in Scheme 1 . When $R^{\prime}$ is an alkyl group, the LUMO occupied by the single electron will be primarily concentrated on the NCCN skeleton, as indicated by simple, well resolved, ESR spectra [9]. However, when $R^{\prime}$ is an aryl group, the LUMO may now be extended, through overlap with the $\pi$ system of the aryl substituents.

${ }^{*}$ Author to whom correspondence should be addressed.
In this paper we present the first results of reactions of $\mathrm{R}_{2} \mathrm{Zn}$ compounds with aryl substituted $\mathrm{DAB}$ systems. Most of the reactions were performed with $N, N^{\prime}$ bis(2,6-di-isopropylphenyl)-1,4-diaza-1,3-butadiene, $\left(\mathrm{i}-\mathrm{Pr}_{2} \mathrm{Ph}\right) \mathrm{N}=\mathrm{CHCH}=\mathrm{N}\left(\mathrm{i}-\mathrm{Pr}_{2} \mathrm{Ph}\right) \quad\left(2,6-\mathrm{i}-\mathrm{Pr}_{2} \mathrm{Ph}-\mathrm{DAB}\right)$, which was first reported by tom Dieck et al. [10]. A special structural feature of this aryl substituted $\alpha$ diimine is the fixed perpendicular orientation of the aryl nuclei with respect to the $\mathrm{C}=\mathrm{N}$ imine moieties as a result of the presence of two large ortho substituents in the aryl group. Also some experiments were carried out with a bis ortho-methyl substituted and a paramethyl substituted phenylDAB, i.e. 2,6- $\mathrm{Me}_{2} \mathrm{Ph}-\mathrm{DAB}$ and 4-MePh-DAB. In the latter aryl-DABs, the rotation around the phenyl $\mathrm{C}_{\text {ipso }}-\mathrm{N}$ axis is less hindered (2,6$\mathrm{Me}_{2} \mathrm{Ph}-\mathrm{DAB}$ ) or not hindered at all (4-MePh-DAB). Consequently, with these aryl-DABs both steric and electronic effects on the group-transfer reaction with $\mathrm{R}_{2} \mathrm{Zn}$ can be studied.

\section{Experimental}

\section{General data}

All experiments were carried out under a dry and oxygen-free nitrogen atmosphere, using standard 


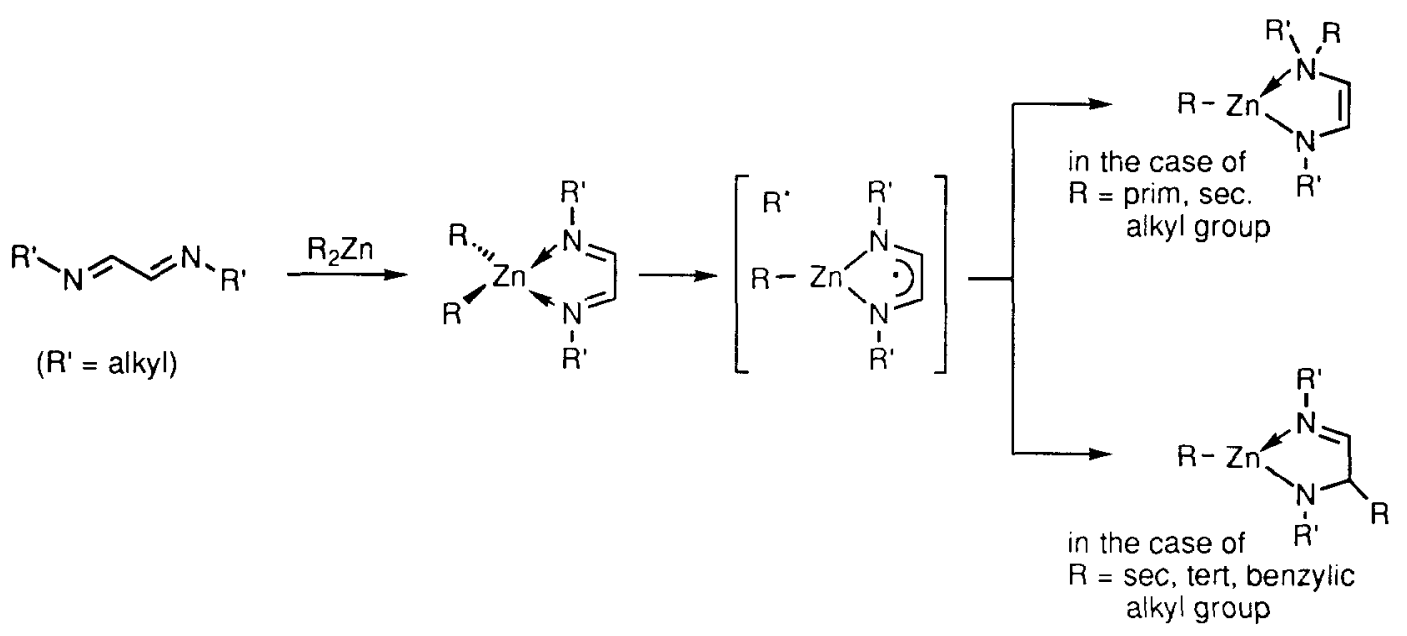

Scheme 1.

Schlenk techniques. Solvents were carefully dried and distilled from sodium/benzophenone prior to use. The diorganozinc compounds $\mathrm{n}-\mathrm{Pr}_{2} \mathrm{Zn}$ (2), n- $\mathrm{Bu}_{2} \mathrm{Zn}$ (3), s$\mathrm{Bu}_{2} \mathrm{Zn}(4), t-\mathrm{Bu}_{2} \mathrm{Zn}(5)$ and $\mathrm{Ph}_{2} \mathrm{Zn}(8)$ were prepared from their corresponding Grignard reagent $(2,4$ and 8 ) or organolithium compound ( 3 and 5 ) with 0.5 equiv. of dry $\mathrm{ZnCl}_{2}$, and purified by distillation at reduced pressure. The starting materials 2,6-i-Pr $2 \mathrm{Ph}-\mathrm{DAB}, 2,6-$ $\mathrm{Me}_{2} \mathrm{Ph}-\mathrm{DAB}, 2,6-\mathrm{i}-\mathrm{Pr}_{2} \mathrm{Ph}-\mathrm{Me}_{2} \mathrm{DAB}$ [10], 4-MePh-DAB [11], $\mathrm{Me}_{2} \mathrm{Zn}$ (1) [12] and (Benzyl) ${ }_{2} \mathrm{Zn}$ (6) [13] were prepared according to literature procedures. All other reagents were purchased from Aldrich Chemical Co. or Janssen Chimica. Elemental analyses were performed by Dornis and Kolbe, Mikroanalytisches Laboratorium, Mülheim a.d. Ruhr, Germany.

General procedure for the alkylation reactions of the $R^{\prime} D A B\left(R^{\prime}=2,6-i-P_{2} P h, 2,6-M e_{2} P h, 4-M e P h\right)$ with $R_{2} Z n$

To a stirred solution of $\mathrm{R}^{\prime} \mathrm{DAB}(10 \mathrm{mmol})$ in $\mathrm{Et}_{2} \mathrm{O}$ $(50 \mathrm{ml})$ was added 1 equiv. of $\mathrm{R}_{2} \mathrm{Zn}$. The red solutions were stirred for $2 \mathrm{~h}$ in the case of 2-7,9 and 10 , and for $16 \mathrm{~h}$ in the case of 8 . The solvent was evaporated in vacuo affording the alkylated products as yelloworange oils (2d, 3d, 5c, 6d and 10) or yellow solids (4d, 8b and 9) in quantitative yicld. Relcvant NMR data of these products and of $\mathbf{1 d}$ (see below) are given in Tables $1\left({ }^{1} \mathrm{H}\right.$ NMR $)$ and $2\left({ }^{13} \mathrm{C} \mathrm{NMR}\right)$.

\section{Synthesis of $\mathrm{MeZn}\left(\mathrm{i}-\mathrm{Pr}_{2} \mathrm{Ph}\right) \mathrm{N}-\mathrm{CH}_{2}-\mathrm{C}(\mathrm{Me})=\mathrm{N}\left(\mathrm{i}-\mathrm{Pr} \mathrm{r}_{2} \mathrm{Ph}\right)$ (Id)}

To a stirred solution of 2,6-i-Pr ${ }_{2} \mathrm{Ph}-\mathrm{DAB}(3.76 \mathrm{~g}, 10$ mmol) in $\mathrm{Et}_{2} \mathrm{O}(50 \mathrm{ml})$ was added 1 equiv. of $\mathrm{Me}_{2} \mathrm{Zn}$ (10 $\mathrm{ml}$ of a $1 \mathrm{M}$ solution in hexane). The red solution was heated at $34^{\circ} \mathrm{C}$ for $36 \mathrm{~h}$ after which a second equivalent of $\mathrm{Me}_{2} \mathrm{Zn}$ was added. The alkylation reaction was completed after an additional heating at $34{ }^{\circ} \mathrm{C}$ for
$36 \mathrm{~h}$. The solvent was evaporated in vacuo affording the alkylated product as an orange oil in quantitative yield.

General procedure for the hydrolyzed products

The alkylated products (1d-4d, 5c, 6d, 7b, 8b, 9 and 10) were dissolved in $\mathrm{Et}_{2} \mathrm{O}(50 \mathrm{ml})$ and 1 equiv. of $\mathrm{H}_{2} \mathrm{O}$ was added. After stirring for $1 \mathrm{~h}$ the solid material was collected by centrifugation and subsequent decantation of the clear solution. The solid was extracted with $\mathrm{Et}_{2} \mathrm{O}(2 \times 10 \mathrm{ml})$. The combined ethereal extracts were concentrated in vacuo, affording the organic products in almost quantitative yield as yellow oils (1 $\mathbf{d}^{\prime}$, $\mathbf{2} d^{\prime}, \mathbf{4} d^{\prime}, \mathbf{6} d^{\prime}, 7 d^{\prime}, 8 b^{\prime}, 9^{\prime}$ and $\left.10^{\prime}\right)$ or yellow solids (3d' and $\mathbf{5} \mathbf{c}^{\prime}$ ).

Anal. Calc. for 1d', $\mathrm{C}_{27} \mathrm{H}_{40} \mathrm{~N}_{2}: \mathrm{C}, 82.60 ; \mathrm{H}, 10.27 ; \mathrm{N}$, 7.13. Found: C, 82.78; H, 10.44; N, 7.26\%. Anal. Calc. for $3 \mathrm{~d}^{\prime}, \mathrm{C}_{30} \mathrm{H}_{46} \mathrm{~N}_{2}: \mathrm{C}, 82.89 ; \mathrm{H}, 10.67 ; \mathrm{N}, 6.44$. Found: C, 82.36; H, 11.10; N, 6.23\%. Anal. Calc. for $\mathbf{4 d}^{\prime}$, $\mathrm{C}_{30} \mathrm{H}_{46} \mathrm{~N}_{2}: \mathrm{C}, 82.89 ; \mathrm{H}, 10.67 ; \mathrm{N}, 6.44$. Found: $\mathrm{C}, 80.10$; $\mathrm{H}, 10.51 ; \mathrm{N}, 6.27 \%$. Anal. Calc. for $5 \mathrm{c}^{\prime}, \mathrm{C}_{30} \mathrm{H}_{46} \mathrm{~N}_{2}$ : C, $82.89 ; \mathrm{H}, 10.67 ; \mathrm{N}, 6.44$. Found: $\mathrm{C}, 82.76 ; \mathrm{H}, 10.80 ; \mathrm{N}$, $6.53 \%$.

Relevant NMR data of these products are given in Tables 3 ( ${ }^{1} \mathrm{H}$ NMR) and $2\left({ }^{13} \mathrm{C}\right.$ NMR).

\section{Reaction of $n-\mathrm{Pr}_{2} \mathrm{Zn}$ with 4-MePhDAB}

The same experimental procedure as described above for the alkylation reactions of $\mathrm{R}_{2} \mathrm{Zn}$ with 2,6-i$\mathrm{Pr}_{2} \mathrm{PhDAB}$ and 2.6- $\mathrm{Me}_{2} \mathrm{PhDAB}$ was followed. The hydrolyzed reaction mixture consisted of the $\mathrm{N}$-alkylated $\left(\mathbf{1 1} \mathbf{b}^{\prime}, \mathbf{6 0 \%}\right)$ and the C-alkylated products with $\left(\mathbf{1 1 d}^{\prime}\right.$, $30 \%$ ) and without a 1,2-hydrogen shift $\left(11 \mathbf{c}^{\prime}, 10 \%\right)$.

Characteristic ${ }^{1} \mathrm{H}$ NMR data of the hydrolyzed $\mathrm{N}$ $\left(\mathbf{1 1}^{\prime}\right)$ and C-alkylated $\left(\mathbf{1 1} \mathbf{c}^{\prime}\right.$ and 11d') products: 11 $\mathbf{b}^{\prime}$ $\delta 6.05$ (dd, $J=5.8 \mathrm{~Hz}, J=12.5 \mathrm{~Hz}, 1 \mathrm{H}, \mathrm{CH}=\mathrm{CH}$ ), 5.46 (br d, $J=12.5 \mathrm{~Hz}, 1 \mathrm{H}, \mathrm{N} H), 5.02(\mathrm{~d}, J=5.8 \mathrm{~Hz}, 1 \mathrm{H}$, 
TABLE 1. Relevant ${ }^{1} \mathrm{H}$ NMR data ${ }^{\mathrm{a}}$ of the alkylated organozinc complexes formed in the reactions of $\mathrm{R}_{2} \mathrm{Zn}$ with $N, N^{\prime}$-di-(2,6-diisopropylphenyl)-1,4-diaza-1,3-butadiene

\begin{tabular}{|c|c|c|c|c|c|c|c|}
\hline $\mathrm{R}=$ & $\mathrm{ZnR}^{b}$ & $\mathrm{~N}=\mathrm{C} R$ & $\mathrm{~N}=\mathrm{CH}$ & $\mathrm{N}-\mathrm{CH}_{2}$ & $\mathrm{~N}-\mathrm{CHR}$ & $H \mathrm{C}=\mathrm{CH}$ & $\mathrm{CH}\left(\mathrm{CH}_{3}\right)_{2}^{\mathrm{c}, \mathrm{d}}$ \\
\hline Id, $\mathrm{Me}$ & $-0.34^{c}$ & $1.21^{\mathrm{e}}$ & & $4.32^{3}$ & & & $2.75,3.79$ \\
\hline 2d, n-Pr & $0.67^{g, i}$ & $i$ & & $4.39^{\mathrm{e}}$ & & & $2.79,3.70$ \\
\hline 3d, $n-B u$ & $0.55^{\mathrm{g} . \mathrm{i}}$ & $\mathbf{i}$ & & $4.45^{\mathrm{e}}$ & & & $2.82,3.82$ \\
\hline 4d, s-Bu & n.o. & $i$ & & $4.41^{\circ}$ & & & $2.83,3.85$ \\
\hline $5 c, t-B u$ & $0.93^{c}$ & $1.20^{\mathrm{c}, \mathrm{j}}$ & $8.22^{\mathrm{f}, \mathrm{k}}$ & & $4.28^{\mathrm{f}, \mathrm{k}}$ & & $\begin{array}{l}2.95,3.10 \\
3.51^{\circ}\end{array}$ \\
\hline Gd, $\mathrm{Bn}$ & $2.12^{\mathrm{e}}$ & $3.17^{\mathrm{e}}$ & & $4.38^{e}$ & & & $2.76,3.64$ \\
\hline $7 \mathbf{d}, \mathrm{Np}$ & $\begin{array}{l}0.71^{\mathrm{e}, 1} \\
0.73^{\mathrm{e}, \mathrm{m}}\end{array}$ & $\begin{array}{l}1.02^{\mathrm{e}, 1} \\
2.13^{\mathrm{e}, \mathrm{m}}\end{array}$ & & $4.68^{\mathrm{e}}$ & & & $2.84,3.69$ \\
\hline $8 b, \mathrm{Ph}$ & & & & & & $\begin{array}{l}5.92^{\mathrm{f}, \mathrm{n}} \\
4.98^{\mathrm{f}, \mathrm{n}}\end{array}$ & $\begin{array}{l}2.91,3.61 \\
3.88^{\circ}\end{array}$ \\
\hline 9, $\mathrm{Et}^{\mathrm{P}}$ & $0.55^{\mathrm{h}}$ & $1.74^{4}$ & & & & & $\begin{array}{l}2.90,3.84 \\
3.96^{\circ}\end{array}$ \\
\hline 10, $\operatorname{Pr}^{r}$ & $0.65^{\mathrm{g}}$ & & & $4.23^{\mathrm{c}}$ & & & $1.95,2.53^{\mathrm{s}, \mathrm{e}}$ \\
\hline
\end{tabular}

${ }^{1}{ }^{1} \mathrm{H}$ NMR spectra were recorded on a Bruker $\mathrm{AC}-200$ or $\mathrm{AC}-300 \mathrm{MHz}$ spectrometer. All values are in ppm using TMS as an external standard $(0.0 \mathrm{ppm})$, in $\mathrm{C}_{6} \mathrm{D}_{6}$ at ambient temperature. ${ }^{\mathrm{b}}$ Only resonance of protons bonded to $\alpha$-carbon ( $\mathrm{ZnC} \mathrm{C}_{\alpha}$ ). $\quad$ 'Resonances were observed as multiplets in a 1:1 ratio. ${ }^{\mathrm{d}} \mathrm{For}$ all compounds the signals of the $\mathrm{CH}\left(\mathrm{CH}_{3}\right)_{2}$ are doublets between 1.0 and 1.5

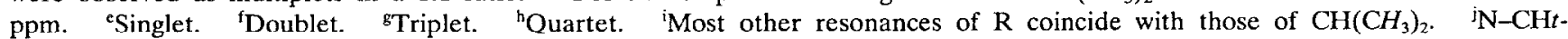
Bu. $\quad{ }^{k}{ }^{3} \mathrm{~J}=1.7 \mathrm{~Hz} . \quad{ }^{\prime} \mathrm{CH}_{2} \mathrm{CMe}_{3} . \quad{ }^{\mathrm{m}} \mathrm{CH}_{2} \mathrm{CMe}_{3} . \quad{ }^{n}{ }^{3} \mathrm{~J}=5.4 \mathrm{~Hz}, Z$-configuration. $\quad{ }^{\circ}$ Resonances were observed as multiplets in a 2:1:1 ratio. PProduct obtained from the reaction of $\mathrm{Et}_{2} \mathrm{Zn}$ with $N, N$ 'di-(2,6-di-methylphenyl)-1,4-diaza-2,3-di-methyl-1,3-butadiene. ${ }^{q}$ One part of $\mathrm{AB}$ pattern of diastereotopic protons of $\mathrm{CCH}_{2} \mathrm{CH}_{3}$ (other part falls under i-Pr resonances). 'Product obtained from the reaction of $\mathrm{n}-\mathrm{Pr}_{2} \mathrm{Zn}$ with $N, N^{\prime}$-di-(2,6-di-methylphenyl)-1,4-diaza-1,3-butadiene. ' $R$ Resonances of methyl groups.

TABLE 2. Relevant ${ }^{13} \mathrm{C}$ NMR data ${ }^{a}$ of the alkylated organozinc products and hydrolyzed products (between brackets) of the reactions of $\mathrm{R}_{2} \mathrm{Zn}$ with $N, N^{\prime}$-di-(2,6-di-isopropylphenyl)-1,4-diaza-1,3-butadiene

\begin{tabular}{|c|c|c|c|c|}
\hline Compound & $\mathrm{ZnC}$ & $\mathrm{N}=C \mathrm{R}$ & $\mathrm{N}-\mathrm{CH}_{2}$ & Other \\
\hline $1 d\left(1 d^{\prime}\right)$ & -15.9 & $184.8(167.8)$ & $66.9(58.2)$ & $18.0(18.9)(\mathrm{N}=\mathrm{CMe})$ \\
\hline $2 d\left(2 d^{\prime}\right)$ & 11.6 & $187.6(170.6)$ & $66.0(65.9)$ & \\
\hline $3 d\left(3 d^{\prime}\right)$ & 8.5 & $187.9(170.7)$ & $64.9(56.3)$ & \\
\hline $4 d\left(4 d^{\prime}\right)$ & 17.2 & $191.9(173.9)$ & $60.7(53.3)$ & \\
\hline $5 c\left(5 c^{\prime}\right)$ & 40.2 & & & $\begin{array}{l}182.9(167.4)^{\mathrm{b}}, 81.2(71.9)^{\mathrm{c}} \\
28.4,23.5(27.2)^{\mathrm{d}}\end{array}$ \\
\hline $6 d\left(6 d^{\prime}\right)$ & 17.6 & $187.1(168.5)$ & $65.6(56.7)$ & \\
\hline $7 \mathbf{b}\left(7 \mathbf{b}^{\prime}\right)$ & n.o. & $187.1(169.7)$ & $66.9(65.9)$ & $\begin{array}{l}46.6(46.5)^{\mathbf{e}} \\
35.6,30.4(24.5)^{\mathrm{f}}\end{array}$ \\
\hline $\mathbf{8 b}\left(\mathbf{8} \mathbf{b}^{\prime}\right)$ & & & & $132.5(147.4)^{\mathrm{g}}, 99.7(106.3)^{\mathrm{h}}$ \\
\hline $9\left(9^{\prime}\right)^{i}$ & -1.8 & $191.0(175.2)^{i}$ & & \\
\hline $10^{\prime \mathrm{k}}$ & 11.9 & 187.8 & 61.2 & \\
\hline
\end{tabular}

${ }^{\text {a }}{ }^{13} \mathrm{C}$ NMR spectra were recorded on a Bruker AC-200 or AC-300 $\mathrm{MHz}$ spectrometer. All values are in ppm using TMS as an external standard $(0.0 \mathrm{ppm})$, in $\mathrm{C}_{6} \mathrm{D}_{6}$ at ambient temperature. ${ }^{\mathrm{b}}(\mathrm{N}=\mathrm{CH}) . \quad{ }^{\mathrm{C}} \mathrm{N}-\mathrm{C}(\mathrm{H}) \mathrm{CMe}_{3} . \quad{ }^{\mathrm{d}} \mathrm{CMe}_{3} . \quad{ }^{\mathrm{e}} \mathrm{N}=\mathrm{CCH}_{2} \mathrm{CMe}_{3}$. ${ }^{\mathrm{f}} \mathrm{N}=\mathrm{CCH}_{2} \mathrm{CMe}_{3} . \quad{ }^{\mathrm{g}} \mathrm{Ar}(\mathrm{Ph}) \mathrm{NCH}=\mathrm{CHNAr} .{ }^{\mathrm{h}} \mathrm{Ar}(\mathrm{Ph}) \mathrm{NCH}=\mathrm{CHNAr}$. 'Product obtained from the reaction of $\mathrm{Et} \mathrm{Zn}_{2}$ with $N, N$ '-di(2,6-dimethylphenyl)-1,4-diaza-2,3-dimethyl-1,3-butadiene (b). ${ }^{\mathrm{i}} \mathrm{N}=C \mathrm{Me}$. ${ }^{\mathrm{k}} \mathrm{C}$-alkylated product obtained from the reaction of $\mathrm{n}$ $\mathrm{Pr}_{2} \mathrm{Zn}$ with $N, N^{\prime}$-di-(2,6-di-methylphenyl)-1,4-diaza-1,3-butadiene (c).

$\mathrm{CH}=\mathrm{CH}) ; 11 \mathrm{c}^{\prime} 7.53(\mathrm{~d}, J=6.2 \mathrm{~Hz}, \mathrm{~N}=\mathrm{CH}) ; \mathbf{1 1 d}^{\prime} \delta$ $5.26(\mathrm{br}, 1 \mathrm{H}, \mathrm{N} H), 4.68$ (br d, $2 \mathrm{H} \mathrm{N}-\mathrm{CH}_{2}$ ).

\section{Results}

The reactions of $N, N^{\prime}$-bis(2,6-di-isopropylphenyl)1,4-diaza-1,3-butadiene $\left(2,6-\mathrm{i}-\mathrm{Pr}_{2} \mathrm{Ph}-\mathrm{DAB}\right)$ with the diorganozinc compounds $\mathrm{R}_{2} \mathrm{Zn}(\mathrm{R}=$ methyl (1), $\mathrm{n}$-propyl (2), n-butyl (3), sec-butyl (4), tert-butyl (5), benzyl (6), neopentyl (7) and phenyl (8) were performed in diethyl ether or hexane at room temperature and resulted in the immediate, quantitative, formation of the dark red 1:1 coordination complexes 1a-8a (see Scheme 2). During the next $2 \mathrm{~h}$, the color of the solutions slowly changed from red to yellow except for $\mathrm{Me}_{2} \mathrm{Zn}(2,6-\mathrm{i}-$ 
TABLE 3. Relevant ${ }^{\mathrm{I}} \mathrm{H}$ NMR data ${ }^{\mathrm{a}}$ of the hydrolyzed alkylated products formed in the reactions of $\mathrm{R}_{2} \mathrm{Zn}$ with $N, N^{\prime}$-di-(2,6-diisopropylphenyl)-1,4-diaza-1,3-butadiene

\begin{tabular}{|c|c|c|c|c|c|c|c|}
\hline $\mathrm{R}=$ & $\mathrm{N}=\mathrm{C} R$ & $\mathrm{~N}=\mathrm{CH}$ & $\mathrm{N}-\mathrm{CH}_{2}{ }^{\mathrm{b}}$ & N-CHR & $\mathrm{N} H^{\mathrm{b}}$ & $H C=\mathrm{CH}$ & $\mathrm{CH}\left(\mathrm{CH}_{\imath)}\right)^{\mathrm{c}, \mathrm{d}}$ \\
\hline 1d', Me & $1.21^{\mathrm{e}}$ & & $3.70^{\mathrm{f}}$ & & $5.21^{\mathrm{g}}$ & & $2.84,3.58$ \\
\hline $2 \mathbf{d}^{\prime}, \mathbf{n}-\operatorname{Pr}$ & $0.48^{g}, 1.85^{i, j}$ & & $3.88^{f}$ & & $5.29^{\mathrm{g}}$ & & $2.90,3.64$ \\
\hline $3 d^{\prime}, n-B u$ & $0.60^{\mathrm{s}}, 1.92^{\mathrm{i}, \mathrm{i}}$ & & $3.93^{f}$ & & $5.33^{\mathrm{g}}$ & & $2.92,3.67$ \\
\hline $4 d^{\prime}, s-B u$ & $\begin{array}{l}0.55^{\mathrm{g}, \mathrm{j}}, 0.72^{\mathrm{f}} \\
2.33^{\mathrm{i}}\end{array}$ & & $\begin{array}{l}3.89^{k} \\
4.02^{k}\end{array}$ & & $5.22^{c}$ & & $2.88,3.62$ \\
\hline $5 c^{\prime}, t-B u$ & $1.19^{\mathrm{e}, 1}$ & $7.55^{\mathrm{f}, \mathrm{m}}$ & & $4.15^{\mathrm{h}, \mathrm{m}, \mathrm{n}}$ & $3.88^{\mathrm{f}, \mathrm{n}}$ & & $2.49,3.47$ \\
\hline $\mathbf{G d}^{\prime}, \mathrm{Bn}$ & $3.17^{\mathrm{e}}$ & & $3.78^{e}$ & & $5.18^{\mathrm{e}}$ & & $2.94,3.46$ \\
\hline $7 \mathbf{b}^{\prime}, \mathrm{Np}$ & $\begin{array}{l}0.67^{\mathrm{e}, \mathrm{o}} \\
1.97^{\mathrm{e}, \mathrm{p}}\end{array}$ & & & $3.94^{\mathrm{e}}$ & $5.34^{\mathrm{e}}$ & & $2.90,3.62$ \\
\hline $\mathbf{8 \mathbf { b } ^ { \prime } , \mathrm { Ph }}$ & & & & & $4.43^{\mathrm{f}, \mathrm{q}}$ & $\begin{array}{l}5.18^{\mathrm{f}, \mathrm{r}} \\
5.39^{\mathrm{h}, \mathrm{q}, \mathrm{r}}\end{array}$ & $3.20,3.38$ \\
\hline $9^{\prime}, \mathrm{Et}^{\mathrm{s}}$ & $1.55,1.96^{\mathrm{t}, \mathrm{i}}$ & & & & $5.41^{\mathrm{e}}$ & & $\begin{array}{l}2.91,3.06 \\
3.78^{u}\end{array}$ \\
\hline $10^{\prime}, \mathrm{n}-\operatorname{Pr}^{v}$ & $0.45^{\mathrm{g}}$ & & $3.78^{e}$ & & n.o. & & $2.37,1.96^{\mathrm{w}}$ \\
\hline
\end{tabular}

${ }^{2}{ }^{1} \mathrm{H}$ NMR spectra were recorded on a Bruker AC-200 or AC-300 spectrometer. All values are in ppm using TMS as an external standard $(0.0 \mathrm{ppm})$ in $\mathrm{C}_{6} \mathrm{D}_{6}$ at ambient temperature. ${ }^{\mathrm{b}}{ }^{3} J=6.2-6.4 \mathrm{~Hz}$. ${ }^{c}$ Resonances were found as multiplets in a $1: 1$ ratio.

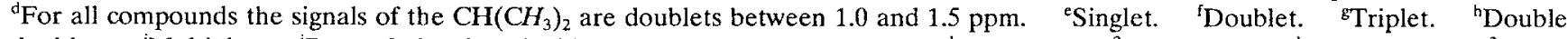
doublet. ${ }^{\mathrm{i}}$ Multiplet. ${ }^{\mathrm{i}}$ Rest of signals coincides with those of $\mathrm{CH}\left(\mathrm{CH}_{3}\right)_{2} . \quad{ }^{\mathrm{k}} \mathrm{AB}$ pattern, ${ }^{2} J=18.5 \mathrm{~Hz} . \quad{ }^{\mathrm{j}} \mathrm{Nm} \mathrm{CH} t-B u . \quad \mathrm{m}{ }^{3} J=5.9$ Hz. ${ }^{n}{ }^{3} J=11.4 \mathrm{~Hz} . \quad{ }^{\circ} \mathrm{CH}_{2} \mathrm{CMe}_{3} . \quad{ }^{\mathrm{P}} \mathrm{CH}_{2} \mathrm{CMe}_{3} . \quad{ }^{\mathrm{q}}{ }^{3} \mathrm{~J}=11.1 \mathrm{~Hz} . \quad{ }^{\mathrm{r}} \mathrm{J}=6.8 \mathrm{~Hz}$., indicating a $Z$-configuration. $\quad{ }^{\mathrm{s}} \mathrm{Hydrolyzed}$ product from the reaction of $\mathrm{Et}_{2} \mathrm{Zn}$ with $N, N^{\prime}$-di-(2,6-dimethylphenyl)-1,4-diaza-2,3-dimethyl-1,3-butadiene. 'Diastereotopic $\mathrm{CCH}_{2} \mathrm{CH}_{3}$ protons. "Resonances were found as multiplets in a $1: 1: 2$ ratio. " $\mathrm{C}$-alkylated product obtained from the reaction of $\mathrm{n}-\mathrm{Pr}_{2} \mathrm{Zn}$ with $N, N^{\prime}$-di-(2,6-dimethylphenyl)-1,4-diaza-1,3-butadiene. $\quad{ }^{\text {w } R e s o n a n c e s ~ o f ~ m e t h y l ~ g r o u p s . ~}$

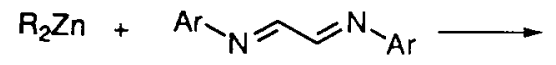

$\mathrm{R}=\mathrm{Me}(1), n-\operatorname{Pr}(2), n-\mathrm{Bu}(3), s-\mathrm{Bu}(4)$, $t$-Bu (5), Bn (6), Np (7), Ph (8) $\mathrm{Ar}=2,6 \mathrm{di}$-isopropylphenyl

Scheme 2.

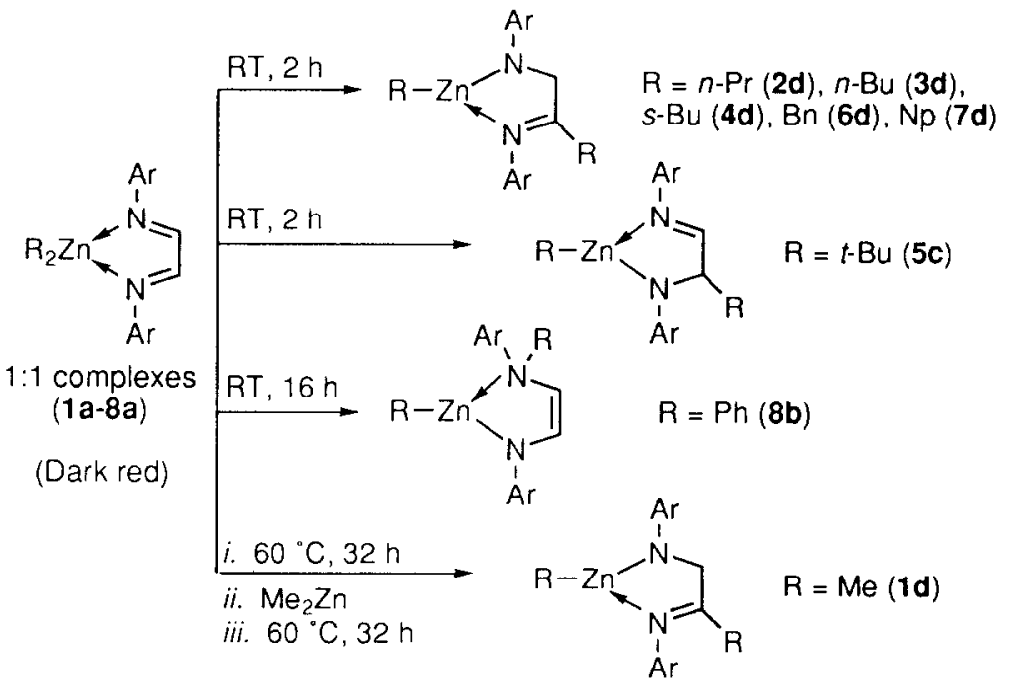

$\left.\mathrm{Pr}_{2} \mathrm{Ph}-\mathrm{DAB}\right)(\mathbf{1 a})$ and $\mathrm{Ph}_{2} \mathrm{Zn}\left(2,6-\mathrm{i}-\mathrm{Pr}_{2} \mathrm{Ph}-\mathrm{DAB}\right)(8 \mathrm{a})$, in which cases the red color remained. This color change is indicative of the occurrence of an alkyl group transfer from zinc to the chelate-bonded DAB system $[8,9]$. This alkyl group transfer resulted in C-alkylated products for the primary (2, 3 and 7 ) and secondary alkyl (4) and benzyl (6) zinc compounds. In these cases, products are also formed that originate from a subsequent hydrogen shift from the alkylated carbon of the $\mathrm{DAB}$ skeleton to the neighboring imine $\mathrm{C}$ atom, i.e. products 2d-4d, 6d and 7d (see Scheme 2).

The coordination complex $\mathrm{Me}_{2} \mathrm{Zn}\left(2,6-\mathrm{i}-\mathrm{Pr}_{2} \mathrm{Ph}-\mathrm{DAB}\right)$ (1a) formed in the reactions with dimethylzinc, is stable at room temperature. Quantitative conversion of this complex to the C-alkylated product Id could only be brought about by boiling it in diethyl ether for at least $72 \mathrm{~h}$, provided that after about $36 \mathrm{~h}$ a second equivalent of $\mathrm{Me}_{2} \mathrm{Zn}$ was added to the solution. The corresponding 
complex with diphenylzinc, $\mathbf{8 a}$, is less stable and is quantitatively converted into the $\mathrm{N}$-alkylated product $\mathbf{8 b}$ already after $16 \mathrm{~h}$ at room temperature. The tertiary dialkylzinc compound $\mathrm{t}-\mathrm{Bu}_{2} \mathrm{Zn}$ reacted with 2,6-i-Pr${ }_{2} \mathrm{Ph}-$ $\mathrm{DAB}$ to give the C-alkylated product 5c only, i.e. without a subsequent hydrogen shift. Even prolonged boiling in hexane $\left(16 \mathrm{~h}\right.$ at $\left.70^{\circ} \mathrm{C}\right)$ did not cause such a shift.

The conversion of the dibutylzinc complex of $\mathbf{3 a}$ into 3d was followed by means of ${ }^{1} \mathrm{H}$ NMR spectroscopy in benzene. It appeared that 3d was formed directly and an intermediate C-alkylated species without subsequent $\mathrm{H}$ shift, cf. $\mathbf{5 c}$, was not detected.

In contrast to the other primary dialkylzinc compounds 1-3, $\mathrm{Et}_{2} \mathrm{Zn}$ did not react with 2,6-i- $\mathrm{Pr}_{2} \mathrm{Ph}-\mathrm{DAB}$ to give a stable alkylated product but instead only decomposition products were formed. However, the reaction of $\mathrm{Et}_{2} \mathrm{Zn}$ with the methyl-substituted derivative of 2,6-i- $\mathrm{Pr}_{2} \mathrm{Ph}-\mathrm{DAB}$, i.e. $\left(\mathrm{i}-\mathrm{Pr}_{2} \mathrm{Ph}\right) \mathrm{N}=\mathrm{CMeCMe}=\mathrm{N}(\mathrm{i}-$ $\left.\mathrm{Pr}_{2} \mathrm{Ph}\right)\left(\mathrm{i}-\mathrm{Pr}_{2} \mathrm{Ph}-\mathrm{Me}_{2} \mathrm{DAB}\right)$, resulted in the formation of the C-alkylated product 9 (eqn. (1)).

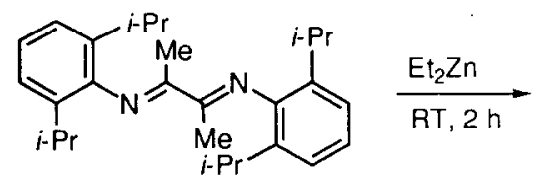

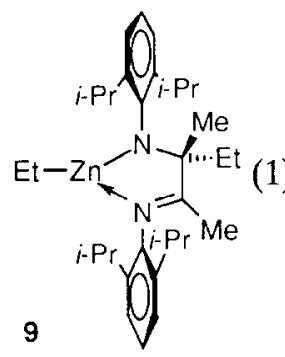

In order to study whether C-alkylation of 2,6-i- $\mathrm{Pr}_{2} \mathrm{Ph}$ $\mathrm{DAB}$ by dialkylzinc compounds is the result of steric or electronic effects, we studied the reactions of $n$ $\mathrm{Pr}_{2} \mathrm{Zn}$ with two other aryl substituted $\mathrm{R}^{\prime} \mathrm{DAB}\left(\mathrm{R}^{\prime}=2,6-\right.$ dimethylphenyl, $R^{\prime}=4$-methylphenyl) ligands which have ortho substituents of different sizes. In the case of 2,6- $\mathrm{Mc}_{2} \mathrm{Ph}-\mathrm{DAB}$, a quantitative formation of the Calkylated product 10 with hydrogen shift was observed (eqn. (2)), while 4-MePh-DAB gave a mixture of the $\mathrm{N}$-alkylated product 11b $(60 \%)$, and two C-alkylated products, one, 11d, with a subsequent hydrogen shift and a second, 11c, without such a shift (30 and 10\% yield, respectively) (eqn. (3))

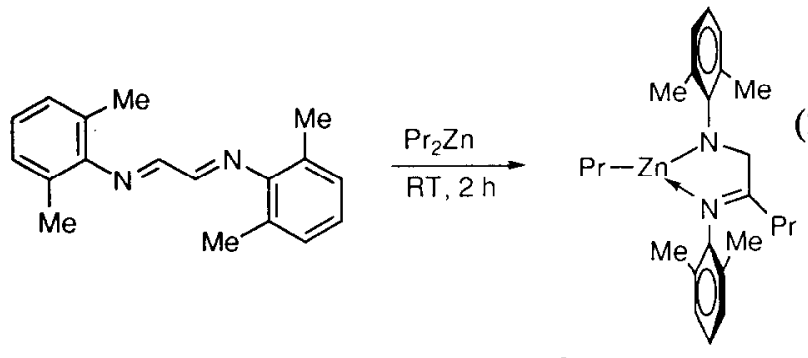

10

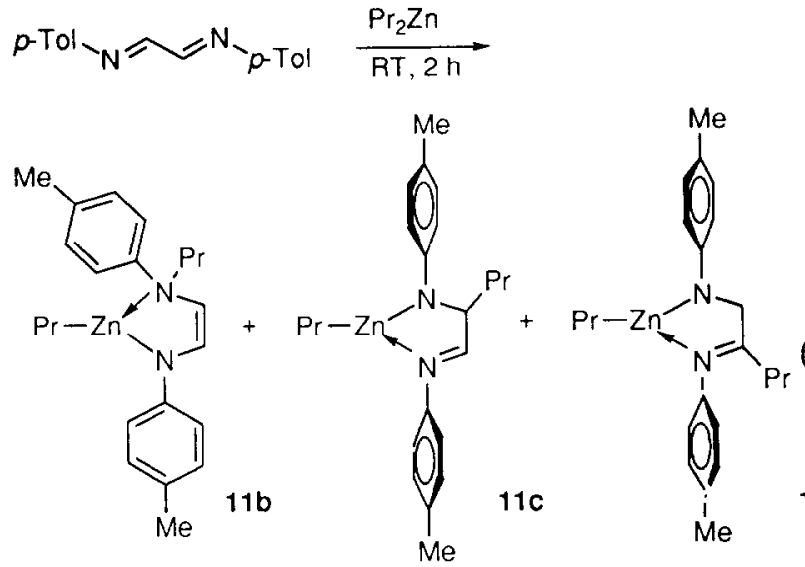

11d

Hydrolysis of the alkylated organozincDAB compounds with $\mathrm{H}_{2} \mathrm{O}$ gave the organic alkylated products $1 d^{\prime}-4 d^{\prime}, 5 c^{\prime}, 6-7 d^{\prime}, 8 b^{\prime}, 9^{\prime}$ and $10^{\prime}$ in excellent yield (eqns. (4)-(7)).

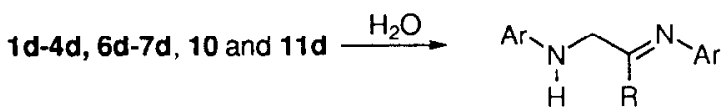

$$
\begin{aligned}
& \mathrm{Ar}=2,6-i-\mathrm{Pr}_{2} \mathrm{Ph} \\
& R=\operatorname{Me}\left(1 d^{\prime}\right), \operatorname{Pr}\left(2 d^{\prime}\right), B u\left(3 d^{\prime}\right) \\
& s-\mathrm{Bu} \text { (4d'), Bn (6d') and } \mathrm{Np} \text { (7d') } \\
& \mathrm{Ar}=2,6-\mathrm{Me}_{2} \mathrm{Ph}, \mathrm{R}=\operatorname{Pr}\left(10^{\prime}\right) \\
& \mathrm{Ar}=4-\mathrm{MePh}, \mathrm{R}=\operatorname{Pr}\left(11 \mathrm{~d}^{\prime}\right) \\
& 5 c
\end{aligned}
$$

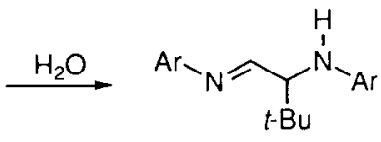

$$
\begin{aligned}
& 5 c^{\prime}: \mathrm{R}=t-\mathrm{Bu}, \mathrm{Ar}=2,6-i-\mathrm{Pr}_{2} \mathrm{Ph} \\
& \text { 11c: }: R=\operatorname{Pr}, A r=4-M e P h \\
& 8 b \\
& \stackrel{\mathrm{H}_{2} \mathrm{O}}{\longrightarrow} \mathrm{Ar}-\overbrace{\mathrm{N}_{\mathrm{H}}}^{\longrightarrow} \overbrace{\substack{1 \\
\mathrm{~N}^{-}}}^{-\mathrm{Ar}} \\
& 8 b^{\prime}: \mathrm{R}=\mathrm{Ph}, \mathrm{Ar}=2,6-i-\mathrm{Pr}_{2} \mathrm{Ph} \\
& 11 b^{\circ}: R=P r, A r=4-M e P h
\end{aligned}
$$

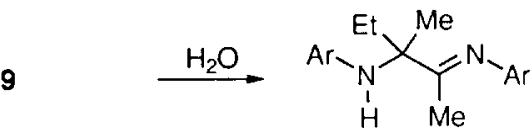

$$
\begin{aligned}
& 9^{\prime}: \mathrm{Ar}=2,6-i-\mathrm{Pr}_{2} \mathrm{Ph}
\end{aligned}
$$

\section{Discussion}

Steric effects

Our results show that replacement of $\mathrm{N}$-alkyl by $\mathrm{N}$ aryl substituents in DAB systems has a large influence on the course of group-transfer reactions with diorganozinc reagents. The most outstanding fact is that reactions of $\mathrm{i}-\mathrm{Pr}_{2} \mathrm{Ph}-\mathrm{DAB}$ with dialkylzinc compounds 
result in the exclusive formation of $\mathrm{C}$-alkylated products. We believe that this is caused by the steric effects of the bis-ortho-substituted 2,6-di-isopropylphenyl substituents on the imine- $\mathrm{N}$ atoms. Thesc effcets have bcen described earlier by Vrieze and co-workers [14] for the reactions of $\mathrm{N}$-substituted $\mathrm{DAB}$ ligands with $\mathrm{Ru}_{3}(\mathrm{CO})_{12}$. They found that the introduction of ortho-methyl substituents (2,6-xylyl or mesityl) in $N$-aryl-DAB, or of methyl substituents in the $\beta$ or $\gamma$ positions of $N$-alkyl$\mathrm{DAB}$, gives rise to a fixed orientation of the aryl rings and alkyl chain perpendicular to the Ru-NCCN chelate plane. Similarly, the bis ortho-isopropyl substituted arylDAB ligand used in the present study, i.e. $N, N^{\prime}$-bis(2,6di-isopropylphenyl)-1,4-diaza-1,3-butadiene, can be expected to have its $\mathrm{N}$-aryl groups fixed perpendicularly to the NCCN chelate ring plane. In this way, the reactivity of the $\mathrm{i}-\mathrm{Pr}_{2} \mathrm{Ph}-\mathrm{DAB}$ ligand towards dialkylzinc compounds, as compared with that of the previously studied alkyl-group-substituted DAB ligands, will be changed because alkylation at the $\mathrm{N}$ atoms is prevented. In fact, the reaction of $n-\mathrm{Pr}_{2} \mathrm{Zn}$ with $\mathrm{Me}_{2} \mathrm{Ph}-\mathrm{DAB}$ shows that the steric hindrance caused by ortho-methyl substituents is already sufficient to direct the group transfer entirely to the neighboring $\mathrm{C}$ atom.

\section{Electronic effects}

The reaction of $\mathrm{n}-\mathrm{Pr}_{2} \mathrm{Zn}$ with 4-MePh-DAB which is electronically comparable to $\mathrm{i}-\mathrm{Pr}_{2} \mathrm{Ph}-\mathrm{DAB}$ and $\mathrm{Me}_{2} \mathrm{Ph}$ $\mathrm{DAB}$ but lacks the ortho substituents in the aryl ring, gave $60 \% \mathrm{~N}$-alkylation and $40 \% \mathrm{C}$-alkylation. This mixture of products indicates that steric effects no longer determine the alkylation of the NCCN skeleton, but that electronic effects are coming into play. Two electronic effects can be recognized which may influence the regioselectivity of the alkyl-group transfer. In the first place, the electron-withdrawing character of the $\mathrm{N}$-aryl substituents will increase the electrophilicity of the $\mathrm{N}$ atoms and therefore their susceptibility to alkylation. Secondly, the delocalization of the electronspin density within the intermediate organozinc radicals, [RZnAr-DAB] (see Scheme 1), will lower the spin density on the $\mathrm{N}$ atom. In the case of $\mathrm{i}-\mathrm{Pr}_{2} \mathrm{Ph}-\mathrm{DAB}$ and $\mathrm{Me}_{2} \mathrm{Ph}-\mathrm{DAB}$ ligands, spin delocalization into the phenyl rings is unlikely, since the ortho substituents of the aryl rings force them in a perpendicular position relative to the $\mathrm{Zn}-\mathrm{NCCN}$-chelate ring (vide supra).

However, rotation of the aryl ring around the $\mathrm{C}_{i p s o}-\mathrm{N}$ bond in 4-MePh-DAB has a lower rotation barrier and the rotamer in which this ring is coplanar with the $\mathrm{Zn}-\mathrm{NCCN}$ chelate ring will be more likely. This rotamer allows overlap between the $\pi$-aryl MOs and the NCCN LUMO and as a consequence the spin density at the $\mathrm{N}$ atoms (the spin density in [RZnt-BuDAB] radicals is c. $60 \%$ at the $\mathrm{N}$ atoms and $40 \%$ at the $\mathrm{C}$ atoms) will decrease because of delocalization in the aryl rings and the susceptibility of the $\mathrm{N}$ atoms for alkylation will decrease, cf. ESR spectra and computational data in ref. 9. We believe that this electronic effect is responsible for the observed $40 \% \mathrm{C}$ - and $60 \% \mathrm{~N}$ alkylation. (In the case of t-BuDAB primary alkyl radicals give rise to quantitative $\mathrm{N}$-alkylation [9]). We recently observed such conjugation in two solid-state structures of two organoaluminum-DAB complexes, i.e. $\mathrm{Me}_{2} \mathrm{Al}\left(\mathrm{ArN}-\mathrm{CH}_{2}-\mathrm{C}(\mathrm{Me})=\mathrm{NAr}\right) \quad(\mathrm{Ar}=p$-tolyl or $p$ methoxyphenyl). In each of these, one of the aryl rings was found to be planar to the five-membered aluminium-NCCN chelate ring [15].

The reaction of $\mathrm{t}-\mathrm{Bu}_{2} \mathrm{Zn}$ with $\mathrm{i}-\mathrm{Pr}_{2} \mathrm{Ph}-\mathrm{DAB}$ gives the $\mathrm{C}$-alkylated product $\mathbf{5 c}$, analogous to the reaction of $\mathrm{t}-\mathrm{Bu}_{2} \mathrm{Zn}$ with $\mathrm{t}$-BuDAB [8]. In the latter case, steric interference between the $\mathrm{t}-\mathrm{Bu}$ substituents on the $\mathrm{N}$ atoms and the bulky alkyl groups already prevent $\mathrm{N}$ alkylation and a further increase of steric strain will have no effect.

The products $1 \mathbf{d}-\mathbf{4 d}$, $6 \mathbf{d}$ and $\mathbf{7 d}$ are formally the result of C-alkylation followed by a hydrogen shift. However, the initial C-alkylated products have never been observed, which leaves open the question of the sequence of the steps. Also the hydrogen shifts have never been observed in reactions of $\mathrm{R}^{\prime} \mathrm{DAB}\left(\mathrm{R}^{\prime}=\right.$ alkyl) with dialkylzinc compounds. Products like 1d-4d, Gd and $\mathbf{7 d}$, however, have been commonly isolated from reactions of $\mathrm{R}^{\prime} \mathrm{DAB}\left(\mathrm{R}^{\prime}=\right.$ alkyl or aryl) with $\mathrm{R}_{3} \mathrm{Al}$ $(\mathrm{R}=\mathrm{Me}, \mathrm{Ph})$, and in some cases the initially formed C-alkylated intermediate was detected [16]. It, therefore, seems plausible that the products $1 d-4 d, 6 d$ and $7 d$ are likewise formed via the initial formation of such intermediates. The subsequent hydrogen shift may be explained in terms of release of steric strain. Within an initially formed $\mathrm{C}$-alkylated intermediate, much steric interference exists between the introduced alkyl group and the ortho-aryl substituents (Fig. 1(a)). After a hydrogen shift, the alkyl group is now bonded to a $\mathrm{sp}^{2}$ carbon, and points in a direction between the orthoaryl substituents, which alleviates steric strain (Fig. 1(b)).

In the case of $\mathbf{5 c}$, a large tert-butyl group is introduced in the alkylation reaction. A hydrogen shift in this case would result in an increase of steric interference with the aryl substituents in the product, and consequently it does not occur.

In the two alkylated organoaluminum- $\mathrm{DAB}$ derivatives mentioned before, i.e. $\mathrm{Me}_{2} \mathrm{Al}\left(\mathrm{ArN}-\mathrm{CH}_{2}-\mathrm{C}\right.$ $(\mathrm{Me})=\mathrm{NAr}),(\mathrm{Ar}=p$-tolyl or $p$-methoxyphenyl $)$, the aryl substituents bound to the nitrogen atoms lack large groups in the ortho positions but even there the least steric interference occurs within the hydrogen-shift products.

The reaction of $\mathrm{Ph}_{2} \mathrm{Zn}$ with i- $\mathrm{Pr}_{2} \mathrm{Ph}-\mathrm{DAB}$, resulting in the $\mathrm{N}$-arylated product $\mathbf{8 b}$, is extraordinary for two 


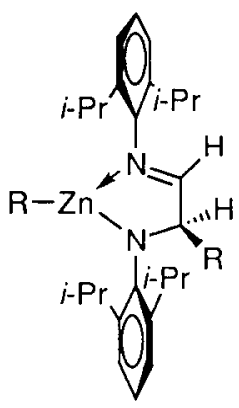

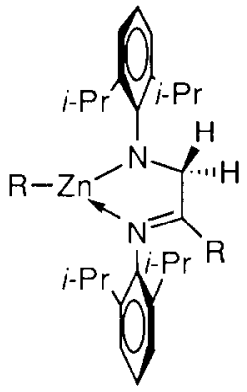
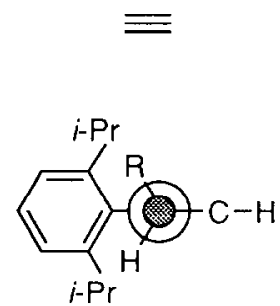

(a)

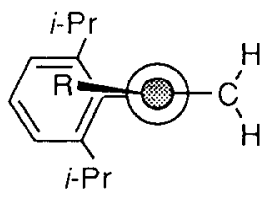

(b)

Fig. 1. Newman projections: (a) vicw along the $C(R) I I-N_{a m i n o}$ bond of a C-alkylation product before a hydrogen shift; (b) view along the $\mathrm{CR}=\mathrm{N}_{\text {imino }}$ bond of a $\mathrm{C}$-alkylation product after a hydrogen shift.

reasons. In the first place, it completely differs from the reaction of $\mathrm{Ph}_{2} \mathrm{Zn}$ with $\mathrm{t}-\mathrm{BuDAB}$, which gives a thermally stable $1: 1$ coordination complex $\mathrm{Ph}_{2} \mathrm{Znt}$ BuDAB that does not convert into a subsequent product $[8,9]$. Secondly, in all reactions of $2,6-\mathrm{i}-\mathrm{Pr}_{2} \mathrm{Ph}-\mathrm{DAB}$ with dialkylzinc compounds we only observe C-alkylation. These facts suggest that the reactivity of $\mathrm{Ph}_{2} \mathrm{Zn}$ towards 2,6-i- $\operatorname{Pr}_{2} \mathrm{Ph}-\mathrm{DAB}$ is not determined by steric effects as discussed above, but by electronic effects. It remains unclear why arylation takes place at the nitrogen atom, leading to a highly crowded nitrogen atom.

\section{Conclusions}

The alkylation of $R^{\prime} D A B$ systems by means of $R_{2} Z n$ can be regioselectively directed (i) by controlling the nature of the dialkylzinc compounds in the case of $\mathbf{R}^{\prime}=$ alkyl, or (ii) by introducing bulky ortho-aryl substituents on the nitrogen atoms of the DAB system. In the first case, tertiary, benzylic and some secondary dialkylzinc compounds give $C$-alkylation in the reaction with R'DAB systems, whereas primary dialkylzinc com- pounds give $\mathrm{N}$-alkylation. This opens the possibility of introducing primary and secondary alkyl groups selectively at the carbon atom of the $\mathrm{DAB}$ as well. In the $\mathrm{DAB}$ system, 2,6-i- $\mathrm{Pr}_{2} \mathrm{Ph}-\mathrm{DAB}$, phenyl groups may also be introduced at the nitrogen atom via $\mathrm{Ph}_{2} \mathrm{Zn}$. So far, this $\mathrm{N}$-selectivity is not understood.

\section{Acknowledgements}

This work was supported in part (E.W.) by the Netherlands Foundation for Chemical Research (SON) with financial aid from the Netherlands Organization for Advancement of Pure Research (NWO).

\section{References}

1 G. van Koten and K. Vrieze, Adv. Organomet, Chem., 21 (1981) 151.

2 K. Vrieze and G. van Koten, Inorg. Chim. Acta, 100 (1985) 79; B.D. Rossenaar, C.J. Kleverlaan, D.J. Stufkens and A. Oskam, Chem. Commun., (1994) 63.

3 E. Wissing, J. Boersma, H. Kleÿn and G. van Koten, Recl. Trav. Chim. Pays-Bas, 112 (1993) 618.

4 H.-W. Frühauf and F. Scils, J. Organomet. Chem., 323 (1987) 67.

5 P.P.M. de Lange, H.-W. Frühauf, M. Kraakman, M. van Wijnkoop, M. Kranenburg, A.H.J.P. Groot, K. Vrieze, J. Fraanje, Y. Wang and M. Numan, Organometallics, 12 (1993) 417.

6 E. Wissing, R.W.A. Havenith, J. Boersma and G. van Koten, Tetrahedron Lett., 33 (1992) 7933.

7 II. tom Dieck and E. Haupt, Chem. Ber., 116 (1983) 1540.

8 G. van Koten, in A. de Meijere and H. tom Dieck (eds.), Organometallics in Organic Synthesis, Springer, Heidelberg, 1987, p. 277.

9 M. Kaupp, H. Stoll, H. Preuss, W. Kaim, T. Stahl, G. van Koten, E. Wissing, W.J.J. Smeets and A.L. Spek, J. Am. Chem. Soc., 113 (1991) 5606.

10 H. tom Dieck, M. Svoboda and T. Greiser, Z. Naturforsch., Teil B, 36 (1981) 823.

11 H. tom Dieck and I.W. Renk, Chem. Ber., 104 (1971) 92.

12 A.L. Galyer and G. Wilkinson, Inorg. Synth., XIX (1979) 253.

13 V. Weissig, R. Beckhaus, U. Banasiak and K.H. Thiele, Anorg. Allg. Chem., 467 (1980) 61.

14 (a) L.H. Staal, L.H. Polm, K. Vrieze, F. Ploeger and C.H. Stam, Inorg. Chem., 20 (1981) 3590; (b) H. van der Poel, G. van Koten, K. Vrieze, M. Kokkes and C.H. Stam, Inorg. Chim. Acta, 39 (1980) 197.

15 J.A. Kanters, G.P.M. van Mier, R.L.L.M. Nijs, F.H. van der Steen and G. van Koten, Acta Crystallogr., Sect. C, 44 (1988) 1391.

16 J.M. Klerks, D.J. Stufkens, G. van Koten and K. Vrieze, J. Organomet. Chem., 181 (1979) 271. 